\title{
Saudi Arabian Community Perceptions on Saudi Female Paramedics: A Cross-Sectional Study
}

\author{
Abdullah Mohammed Alobaid (D) ${ }^{1,2}$, Abdulmajeed Mobrad $\mathbb{D}^{3}$, Cameron Gosling $\mathbb{D}^{2}$, Lisa McKenna $\mathbb{D}^{4}$, \\ Brett Williams $\mathbb{D}^{2}$ \\ 'Prince Sultan bin Abdulaziz College for Emergency Medical Services, King Saud University, Riyadh, Kingdom of Saudi Arabia; ${ }^{2}$ Department of \\ Paramedicine, Faculty of Medicine, Nursing and Health Sciences Monash University, Melbourne, Victoria, Australia; ${ }^{3}$ Department of Emergency \\ Medical Services, Prince Sultan bin Abdulaziz College for Emergency Medical Services, King Saud University, Riyadh, Kingdom of Saudi Arabia; ${ }^{4}$ La \\ Trobe University, School of Nursing and Midwifery, Melbourne, Victoria, Australia \\ Correspondence: Abdullah Mohammed Alobaid, Prince Sultan bin Abdulaziz College for Emergency Medical Services, King Saud University, Riyadh, \\ Kingdom of Saudi Arabia, Tel +966533336396, Email a.alobaid33@gmail.com
}

\begin{abstract}
Introduction: Although emergency medical services (EMS) stakeholders acknowledge the need for both male and female paramedics in the EMS field, the Saudi EMS system is currently only staffed by male paramedics and emergency medical technicians (EMTs) working in EMS organisations.
\end{abstract}

Aim: To understand and explore the Saudi Arabian community's perceptions on engaging Saudi female paramedics in the EMS workforce.

Material and Methods: This was a cross-sectional survey design using convenience sampling of the public in Riyadh city by selfadministered English and Arabic language questionnaires. Questionnaire validity was assessed by face and content validity.

Results: Of the 3603 surveys distributed, 3132 were returned ( $87 \%$ completion response rate). Most respondents were aged between 18 and 29 years $(n=1308,41 \%)$, and the sex distribution was $(n=1646,52.6 \%)$ male and $(n=1486,47.4 \%)$ female. Overall, $77 \%(n=2412)$ of the respondents supported the need for female paramedics in Saudi Arabian ambulance services, and 74.8\% $(\mathrm{n}=2343)$ preferred that female paramedics treated female patients.

Conclusion: This is the first public study to explore Saudi public perceptions about female paramedics in EMS in the Riyadh region, Saudi Arabia. The Saudi public is supportive of female paramedics being employed as paramedics in the country. Moreover, significant differences in perceptions were evidenced in the sex groups over any other factors.

Keywords: emergency medical services, female, paramedic, public perception, Saudi Arabia

\section{Introduction}

The role of Emergency Medical Services (EMS) is to provide patient care in case of emergencies outside of hospital settings, where primary staff members working are paramedics or Emergency Medical Technicians (EMTs). The EMS discipline is recognized as a first responder in case of urgent or emergency medical situations out-of-hospital. ${ }^{1,2}$ In the Kingdom of Saudi Arabia, the EMS can be traced back to 1934; however, emergency medicine itself is a relatively newly developed field in the country that was formalized through the launch of the Saudi Board of Emergency Medicine in 2005. ${ }^{3}$

Emergency Medical Services in the nation are managed by the Saudi Red Crescent Authority (SRCA) through the execution of a third-party model, whereby the Saudi public can access the service by calling $9977^{4,5}$ The operations of the EMS are government-funded, and as of 2016, the SRCA reported having approximately 2000 ambulances around the country. ${ }^{3}$ At present, the EMS model in Saudi Arabia is managed by the Ministry of Health, which comprises both private and government hospitals; however, the contribution of the private sector is limited scope in prehospital settings for outpatient cases. ${ }^{3}$

Research by Khattab et $\mathrm{al}^{3}$ indicates that emergency medicine practice in the country is characterized by the presence of certain challenges, including the delivery of sub-optimal emergency medicine practices. Moreover, the system of emergency medicine delivery is overwhelmed by high demand in certain areas, lack of appropriate medical equipment 
and medicines and shortage of paramedicine staff of both gender. ${ }^{3,6}$ Where the delivery of EMS has previously been dominated by the presence of males only in SRCA in the Kingdom, some female paramedics have entered the field in a bid to enhance and strengthen the EMS where they work currently within hospitals in the country. ${ }^{3}$ This transition aligns with the vision promoted by the Saudi Vision 2030 which recognizes the need to induct more female paramedics into the field. ${ }^{7,8}$ Furthermore, Saudi female paramedics need more motivation that affect to their psychological features level to serve the Saudi community. ${ }^{2}$

The Saudi Arabian community is known to be a conservative culture, sticking to traditional cultural characteristics. ${ }^{9}$ Therefore, the Saudi community's general perceptions of the recruitment of female paramedics into the EMS workforce may not be positive. Despite this, research conducted by Alharthy et $\mathrm{al}^{10}$ found that the introduction of female paramedics within the Saudi community was critical due to cultural aspects, as it was deemed more suitable for female paramedics to care for female patients, especially when their male guardian is not present at the scene of the emergency. The researchers conducted their research with 312 respondents in both medical and nonmedical fields and found a significant percentage strongly agreed with having female paramedics as part of the EMS. The study also found that $30 \%$ of the respondents had even refused to seek medical assistance in cases where female paramedics were not present. Moreover, the research findings also substantiated community perceptions that both male and female paramedics had comparable expertise, and sex was not a defining factor in the ability to manage patients.

Other research conducted by Hamam et $\mathrm{a}^{11}$ concluded that conservative families preferred to have female paramedics attend to female patients further indicating the influence of religious and cultural perceptions regarding the paramedical profession in Saudi Arabia. Khattab et $\mathrm{al}^{3}$ noted that with the legalization of female drivers in Saudi Arabia, the need to introduce a wider proportion of female paramedics within the EMS had become widely acknowledged because they would assist in bridging the existing sex gap in a significantly male-dominated profession.

Nonetheless, female paramedics in the country face challenges, particularly regarding culture and family. Research conducted by ${ }^{12}$ found that female paramedics in the country had familial and social responsibilities, such as taking care of their households and children, which impacted their job capacity. Other barriers were found to be associated with psychological concerns of being a part of the field, in addition to taxing physical demands. The presence of these barriers highlights the need to devise policies for streamlining the entry of female paramedics into the profession and supporting their choice to work as paramedics or EMTs.

The blueprint presented by Saudi Vision 2030 indicates that assimilation of female paramedics would prove to be an effective measure for enhancing the delivery of services because the skill level and expertise of paramedics are not determined by sex. Therefore, it is timely and important that a study examines the perceptions of the Saudi community regarding female paramedics and gauge their views and perspectives about their role within the field of EMS. To inform such work, the present study sought to understand and explore the Saudi Arabian community's perceptions on engaging Saudi female paramedics in the EMS workforce.

\section{Materials and Methods Study Design}

A cross-sectional survey design was used to explore public perceptions towards Saudi female paramedics in Saudi Arabian society in the city of Riyadh. This study followed the Strengthening of the Reporting of Observational Studies in Epidemiology (STROBE) tool. ${ }^{13}$ The main question guiding the study was framed as follows: What are the perceptions of the Saudi community towards Saudi female paramedics?

To help investigate this main question, three sub-questions were stated as

1. Do age groups impact the perceptions of the Saudi community towards Saudi female paramedics?

2. Does sex impact perceptions of the Saudi community towards Saudi female paramedics?

3. Does residential location impact perceptions of the Saudi community towards Saudi female paramedics? 


\section{Setting and Participants}

The study was conducted with the Saudi public in the Riyadh region (capital city of Saudi Arabia). The questionnaire was distributed face-to-face by a data collection team across a diverse range of public places around Riyadh including shopping centers, coffee shops, restaurants, public walking areas and parks during weekends between $4 \mathrm{pm}$ and $11 \mathrm{pm}$, over 1 month in January 2021. The estimated required sample size $(n=385)$ for the survey was calculated using $G$ power software including a 95\% confidence value and 5\% of margin error, considering the population of Riyadh city in 2019 of $8,660,885$ people. ${ }^{14}$ A convenience sampling technique was utilized for the study, and the target population was the Saudi public in Riyadh city. The inclusion and exclusion criteria were (1 respondent must be a Riyadh resident and 2) a minimum age of 18 years.

\section{Instrument}

The questionnaire contained two sections: the first contained six demographic questions comprising sex, age group, nationality, profession, residential area and their experiences of using ambulance services for female family members in the previous 5 years. The demographic questions were categorized as follows: sex, male and female; age groups, 18-29, 30-39, 40-49 and <50 years old; Saudi or non-Saudi nationality; profession as medical, non-medical or unemployed and residential area categorized as one of five areas: north, south, west, east, and middle of Riyadh. The second section included 13 perception items rated on a 1-7 Likert scale, where 1 represented "strongly disagree" and 7 representing "strongly agree". The perception instrument was developed from previous studies by the researchers, a systematic scoping review by Alobaid et al, ${ }^{15}$ a conceptual framework by Alobaid et al, ${ }^{9}$ a qualitative study of perceptions of EMS leaders and supervisors on the challenges faced by female paramedics in Riyadh, Saudi Arabia. ${ }^{12}$

Face and content validity was also conducted on the 19-item instrument by 10 Saudi and non-Saudi paramedic experts, with lengthy experience in the EMS discipline and holding a higher certificate of paramedics. Furthermore, the questionnaire needed to consider the culture and language of respondents, which needed translation of the instruments to Arabic language. ${ }^{16}$ To achieve accuracy of translation and avoid any barriers with study respondents, the primary author and other health translators initially translated the questionnaire from English to Arabic. All translators were healthcare professionals and professional healthcare translators who could speak, read, and write in both languages, Arabic and English, fluently. Subsequently, the primary author approved the first step of the translation process, which followed double independent forward-translation and reconciliation followed by the cognitive testing process to develop a unique Arabic translation. ${ }^{16}$ A pilot study of 10 Saudi public members was invited to test and validate question clarity and logic. In addition, to ensure reliability, a 7-point Likert scale was used to score responses.

\section{Procedures}

Respondents were presented with an electronic-form explanatory statement that provided more information about the purpose of the study, confidentiality, and data storage before completing the survey. The survey was completed electronically by using either a Qualtrics or QR code link and collected in cooperation with a team of 25 paramedic students from the Prince Sultan College for Emergency Medical Services at King Saud University under the supervision of one of the research team members (AM). The data collection team was distributed into five sub-teams, each distributed surveys in different areas of Riyadh. All potential respondents were informed of the purpose of the study, the voluntary nature of participation and anonymity.

\section{Data Analysis}

Responses were collated and then analyzed using the Statistical Package for Social Sciences [SPSS] software version 27.0 [IBM Corp., Armonk, N.Y., USA]. After cleaning and coding, respondents' demographics and scale responses were analyzed using descriptive methods. Normality of the data were tested using skewness, kurtosis and KolmogorovSmirnov tests. Differences in responses were assessed using Chi-squared analysis. Multivariate ordinal logistic regression analyses were used to show associations between respondent demographics and response scale with Coefficient (Coef) 
and $95 \%$ confidence intervals (CIs) reported. Cronbach's alpha coefficient was determined to this study to be 0.724 . The threshold for statistical significance for this study was set at $\mathrm{P}<0.05$.

\section{Ethical Considerations}

Consent was implied when the respondent submitted the survey via the QR code or Qualtrics links. The study was approved by the Monash University Human Ethics Committee (project ID\# 27093) and King Saud University ethical committee (Project ID\# E-21-5652). The main ethical issues considered were respect for person, beneficence and that no harm was caused to the respondent, informed consent and privacy of the respondents. ${ }^{17}$

\section{Results}

\section{Demographic Characteristics}

A total of 3132 completed survey questionnaire were received. The respondents' demographics are reported in Table 1. Most respondents were aged 18-29 years $(n=1308,41 \%)$, male $(n=1646,52.6 \%)$ and were Saudi nationals $(n=3029$, 96.7\%). Most respondents were not medical professionals $(\mathrm{n}=2668,85.1 \%)$. The population was distributed across all areas of Riyadh, with the east recording the highest responses $(\mathrm{n}=909,29.0 \%)$, and the middle recording the lowest responses $(n=417,13.3 \%$. Approximately, one-quarter of the sample $(n=792,25.3 \%)$ reported using the ambulance service for female members of their family in the previous 5 years.

\section{Discussion}

The present study is one of the very first large-scale studies to explore perceptions of the Saudi public in the Riyadh region towards Saudi female paramedics. Saudi society is considered to be conservative and retaining culture and traditions that minimize the development of female paramedics in the field of EMS in the country. These traditions previously forced EMS organizations in Saudi Arabia to employ and train male paramedics and EMTs only to provide services to the Saudi public, ${ }^{10}$ whereas a number of universities in the country have begun to educate and graduate Saudi female paramedics, where fewer of them currently working in Riyadh hospitals. ${ }^{9}$ This study suggests that the public held positive perspectives towards including female paramedics in the field of EMS in the country. However, many significant differences were identified between different groups. Therefore, understanding findings will be discussed in relation to the key differences found according to respondents' demographics.

\section{Gender Groups}

Concerning sex, the study observed a significant difference in most all items except items 5 and 6 , one of the most significant items is the perceptions of the Saudi public around the need for female paramedics to provide EMS services. This finding indicated that most respondents realized the importance of the availability of female paramedics in the Saudi EMS workforce. In addition, Hamam et $\mathrm{al}^{11}$ found that, due to the conservative culture in Saudi Arabia, about one in five of their study respondents preferred female paramedics to treat their female family members and opposed care by male paramedics. Alharthy et $\mathrm{al}^{10}$ also found that female patients in critical situations felt it to be inconvenient to be cared for by male paramedics and they suggested being accompanied by female paramedics to overcome this situation. Similarly, this study confirmed the results of previous studies, where $74.8 \%$ of the respondents preferred female paramedics to treat their family female members, with a significant difference $(\mathrm{p}<0.001)$. Furthermore, the study results show the importance of employing female paramedics, particularly in conservative cultures like Saudi Arabia, where $30 \%$ of the female patients or their male guardians refused EMS contact because no female paramedics were available. ${ }^{10}$ The results of this study indicate that, in a conservative society such as Saudi Arabia, which is characterized by traditional and cultural elements, preference for female paramedics is evident when the patient being treated is female. This is suggestive that the inclusion of female paramedics will continue to prevail in society because of religious beliefs and socio-cultural. Hence, creation of a sexbalanced EMS sector is important with reference to this context. By creating an environment that encourages female paramedics to work in the field, we can ensure that female patients are treated as soon as possible. In other cases, such as with pregnant women, who believe that female paramedics are more likely to be involved in these situations due to their privacies. 
Table I Demographic Data of Public Surveyed $(n=3 \mid 32)$

\begin{tabular}{|c|c|c|}
\hline & $\mathbf{n}$ & $\%$ of Total $n$ \\
\hline \multicolumn{3}{|l|}{ Age group (years) } \\
\hline $18-29$ & 1308 & $4 I$ \\
\hline $30-39$ & 953 & 30.4 \\
\hline $40-49$ & 517 & 16.5 \\
\hline$>50$ & 354 & 11.3 \\
\hline Total & 3132 & 100.0 \\
\hline \multicolumn{3}{|l|}{ Sex } \\
\hline Male & 1646 & 52.6 \\
\hline Female & 1486 & 47.4 \\
\hline Total & 3132 & 100.0 \\
\hline \multicolumn{3}{|l|}{ Nationality } \\
\hline Saudi & 3029 & 96.7 \\
\hline Non-Saudi & 103 & 3.3 \\
\hline Total & 3132 & 100.0 \\
\hline \multicolumn{3}{|l|}{ Job description } \\
\hline Medical & 464 & 14.8 \\
\hline Non-medical & 1301 & 41.5 \\
\hline Unemployed & 1367 & 43.6 \\
\hline Total & 3132 & 100.0 \\
\hline \multicolumn{3}{|c|}{ Residential area in Riyadh } \\
\hline North of Riyadh & 775 & 24.7 \\
\hline South of Riyadh & 517 & 16.55 \\
\hline East of Riyadh & 909 & 29 \\
\hline West of Riyadh & 514 & 16.4 \\
\hline Middle of Riyadh & 417 & 16.3 \\
\hline Total & 3132 & 100.0 \\
\hline \multicolumn{3}{|c|}{ Called for ambulance service for a female family member in the last 5 years } \\
\hline Yes & 792 & 25.3 \\
\hline No & 2340 & 74.7 \\
\hline Total & 3132 & 100.0 \\
\hline
\end{tabular}

Notes: Perception of Saudi public towards Saudi female paramedics. The perceptions of respondents toward female paramedics in Riyadh region are presented in Table 2. Several items related to the importance of the female paramedic role where respondents strongly agreed, including the need for female paramedics in the Saudi Arabian workforce $(n=1192,38.1 \%)$; that Saudi female paramedics should treat both male and female patients in emergencies; and preference for Saudi female paramedics treating their female family members. Items where respondents tended to strongly disagree included, never calling the ambulance services because there were no female paramedics and that Saudi female paramedics would be exposed to violence during their duties. Furthermore, Chi-square test were used to examine and assess the significant differences in responses between groups (Table 3). 
Table 2 Perception of Saudi Public in Riyadh Region, n=3132

\begin{tabular}{|c|c|c|c|c|c|c|c|c|}
\hline $\begin{array}{l}\text { Item } \\
\text { No. }\end{array}$ & Items & $\begin{array}{l}\text { Strongly } \\
\text { Disagree }\end{array}$ & Disagree & $\begin{array}{l}\text { More or } \\
\text { Less } \\
\text { Disagree }\end{array}$ & Neutral & $\begin{array}{l}\text { More or } \\
\text { Less } \\
\text { Agree }\end{array}$ & Agree & $\begin{array}{l}\text { Strongly } \\
\text { Agree }\end{array}$ \\
\hline I & $\begin{array}{l}\text { There is a need for female paramedics in the } \\
\text { Saudi Arabian Ambulance Service }\end{array}$ & 86 (2.7\%) & 91 (2.9\%) & 50 (1.6\%) & $\begin{array}{l}466 \\
(14.9 \%)\end{array}$ & $\begin{array}{l}186 \\
(5.9 \%)\end{array}$ & $\begin{array}{l}1061 \\
(33.9 \%)\end{array}$ & $\begin{array}{l}1192 \\
(38.1 \%)\end{array}$ \\
\hline 2 & $\begin{array}{l}\text { I think Saudi female paramedics have similar } \\
\text { skill levels as male paramedics }\end{array}$ & $95(3 \%)$ & $\begin{array}{l}138 \\
(4.4 \%)\end{array}$ & $\begin{array}{l}113 \\
(3.6 \%)\end{array}$ & $\begin{array}{l}609 \\
(19.4 \%)\end{array}$ & $\begin{array}{l}275 \\
(8.8 \%)\end{array}$ & $\begin{array}{l}1035 \\
(33 \%)\end{array}$ & $\begin{array}{l}867 \\
(27.7 \%)\end{array}$ \\
\hline 3 & $\begin{array}{l}\text { I think Saudi Ambulance Services should } \\
\text { recruit female paramedics }\end{array}$ & $\begin{array}{l}123 \\
(3.9 \%)\end{array}$ & $\begin{array}{l}149 \\
(4.8 \%)\end{array}$ & 81 (2.6\%) & $\begin{array}{l}449 \\
(14.3 \%)\end{array}$ & $\begin{array}{l}280 \\
(8.9 \%)\end{array}$ & $\begin{array}{l}1106 \\
(35.3 \%)\end{array}$ & $\begin{array}{l}944 \\
(30.1 \%)\end{array}$ \\
\hline 4 & $\begin{array}{l}\text { The reason I never called an Ambulance is } \\
\text { because there are no female paramedics }\end{array}$ & $\begin{array}{l}995 \\
(31.8 \%)\end{array}$ & $\begin{array}{l}668 \\
(21.3 \%)\end{array}$ & $\begin{array}{l}111 \\
(3.5 \%)\end{array}$ & $\begin{array}{l}762 \\
(24.3 \%)\end{array}$ & $\begin{array}{l}129 \\
(4.1 \%)\end{array}$ & $\begin{array}{l}306 \\
(9.8 \%)\end{array}$ & $\begin{array}{l}161 \\
(5.1 \%)\end{array}$ \\
\hline 5 & $\begin{array}{l}\text { I think Saudi female paramedics should treat } \\
\text { both male and female patients in emergencies }\end{array}$ & $\begin{array}{l}143 \\
(4.6 \%)\end{array}$ & $\begin{array}{l}150 \\
(4.8 \%)\end{array}$ & $88(2.8 \%)$ & $\begin{array}{l}425 \\
(13.6 \%)\end{array}$ & $\begin{array}{l}214 \\
(6.8 \%)\end{array}$ & $\begin{array}{l}1002 \\
(32 \%)\end{array}$ & $\begin{array}{l}1110 \\
(35.4 \%)\end{array}$ \\
\hline 6 & $\begin{array}{l}\text { I think female paramedics can deal with } \\
\text { children/women/elderly people better than } \\
\text { male paramedics }\end{array}$ & $\begin{array}{l}193 \\
(6.2 \%)\end{array}$ & $\begin{array}{l}259 \\
(8.3 \%)\end{array}$ & $\begin{array}{l}121 \\
(3.9 \%)\end{array}$ & $\begin{array}{l}855 \\
(27.3 \%)\end{array}$ & 281 (9\%) & $\begin{array}{l}746 \\
(23.8 \%)\end{array}$ & $\begin{array}{l}677 \\
(21.6 \%)\end{array}$ \\
\hline 7 & $\begin{array}{l}\text { I prefer a Saudi female paramedic to treat my } \\
\text { wife/mother/sister }\end{array}$ & 67 (2.1\%) & $89(2.8 \%)$ & 48 (1.5\%) & $\begin{array}{l}583 \\
(18.6 \%)\end{array}$ & $\begin{array}{l}202 \\
(6.4 \%)\end{array}$ & $\begin{array}{l}966 \\
(30.8 \%)\end{array}$ & $\begin{array}{l}1177 \\
(37.6 \%)\end{array}$ \\
\hline 8 & $\begin{array}{l}\text { I think that Saudi female paramedics can } \\
\text { balance their family responsibilities and work } \\
\text { duties }\end{array}$ & $\begin{array}{l}110 \\
(3.5 \%)\end{array}$ & $\begin{array}{l}172 \\
(5.5 \%)\end{array}$ & 158 (5\%) & $\begin{array}{l}772 \\
(24.6 \%)\end{array}$ & $\begin{array}{l}338 \\
(10.8 \%)\end{array}$ & $\begin{array}{l}1003 \\
(32 \%)\end{array}$ & $\begin{array}{l}579 \\
(18.5 \%)\end{array}$ \\
\hline 9 & $\begin{array}{l}\text { I think that long hours and shift work might } \\
\text { have an impact on Saudi female paramedics } \\
\text { physically, psychologically and family. }\end{array}$ & $\begin{array}{l}105 \\
(3.4 \%)\end{array}$ & $\begin{array}{l}190 \\
(6.1 \%)\end{array}$ & $\begin{array}{l}108 \\
(3.4 \%)\end{array}$ & $\begin{array}{l}656 \\
(20.9 \%)\end{array}$ & $\begin{array}{l}419 \\
(13.4 \%)\end{array}$ & $\begin{array}{l}1030 \\
(32.9 \%)\end{array}$ & $\begin{array}{l}624 \\
(19.9 \%)\end{array}$ \\
\hline 10 & $\begin{array}{l}\text { I think that Saudi female paramedics can deal } \\
\text { emotionally with any cases they attend to as } \\
\text { paramedics }\end{array}$ & $73(2.3 \%)$ & $\begin{array}{l}140 \\
(4.5 \%)\end{array}$ & $\begin{array}{l}120 \\
(3.8 \%)\end{array}$ & $\begin{array}{l}725 \\
(23.1 \%)\end{array}$ & $\begin{array}{l}394 \\
(12.6 \%)\end{array}$ & $\begin{array}{l}1126 \\
(36 \%)\end{array}$ & $\begin{array}{l}554 \\
(17.7 \%)\end{array}$ \\
\hline II & $\begin{array}{l}\text { I think Saudi female paramedics are physically } \\
\text { capable of dealing with any cases they attend } \\
\text { as paramedics }\end{array}$ & $\begin{array}{l}184 \\
(5.9 \%)\end{array}$ & $\begin{array}{l}300 \\
(9.6 \%)\end{array}$ & $25 \mathrm{I}(8 \%)$ & $\begin{array}{l}715 \\
(22.8 \%)\end{array}$ & $\begin{array}{l}402 \\
(12.8 \%)\end{array}$ & $\begin{array}{l}879 \\
(28.1 \%)\end{array}$ & $\begin{array}{l}401 \\
(12.8 \%)\end{array}$ \\
\hline 12 & $\begin{array}{l}\text { I think that Saudi female paramedics will be } \\
\text { exposed to violence while working with the } \\
\text { Ambulance }\end{array}$ & $\begin{array}{l}611 \\
(19.5 \%)\end{array}$ & 846 (27\%) & $\begin{array}{l}262 \\
(8.4 \%)\end{array}$ & $\begin{array}{l}723 \\
(23.1 \%)\end{array}$ & $\begin{array}{l}257 \\
(8.2 \%)\end{array}$ & $\begin{array}{l}303 \\
(9.7 \%)\end{array}$ & $\begin{array}{l}130 \\
(4.2 \%)\end{array}$ \\
\hline 13 & $\begin{array}{l}\text { I think Saudi female paramedics will suffer } \\
\text { from burnout being a paramedic }\end{array}$ & $\begin{array}{l}193 \\
(6.2 \%)\end{array}$ & $\begin{array}{l}427 \\
(13.6 \%)\end{array}$ & $\begin{array}{l}195 \\
(6.2 \%)\end{array}$ & $\begin{array}{l}839 \\
(26.8 \%)\end{array}$ & $\begin{array}{l}447 \\
(14.3 \%)\end{array}$ & $\begin{array}{l}723 \\
(23.1 \%)\end{array}$ & $\begin{array}{l}308 \\
(9.8 \%)\end{array}$ \\
\hline
\end{tabular}

\section{Age Group}

With reference to the community's perception of female paramedics and their age group, our research found that there was a significant statistical difference between age groups and related items (1, 3, 4, 5, 7, 8 and 9), in comparison with those who were 50 years old and above when gauging their perceptions about the need for female paramedics. There have been limited studies that have focused on establishing associations between the community's perception of Saudi paramedics based on respondents' ages.

According to the Saudi Arabian General Authority for Statistics ${ }^{18}$ the majority of the Saudi population is of younger age between 18 and 29 years, which makes the present study novel, based on their perceptions and plays a critical role in 
Table 3 Chi2 Outcomes for Each Variable, $n=3132$

\begin{tabular}{|c|c|c|c|c|c|c|}
\hline Questionnaire Items & $\begin{array}{l}\text { Age Group } \\
\text { Chi }^{2} \text { (p) }\end{array}$ & $\begin{array}{l}\text { Sex } \\
\text { Chi }^{2}(p)\end{array}$ & $\begin{array}{l}\text { Location } \\
\text { Chi }^{2}(p)\end{array}$ & $\begin{array}{l}\text { Nationality } \\
\text { Chi }^{2} \text { (p) }\end{array}$ & $\begin{array}{l}\text { Job } \\
\text { Chi }^{2}(p)\end{array}$ & $\begin{array}{l}\text { Yes Ambulance } \\
\text { Chi }^{2} \text { (p) }\end{array}$ \\
\hline $\begin{array}{l}\text { I. There is a need for female paramedics in the Saudi } \\
\text { Arabian Ambulance Service }\end{array}$ & $\begin{array}{l}44.62 \\
(<0.001)\end{array}$ & $\begin{array}{c}22.91 \\
(0.001)\end{array}$ & $\begin{array}{l}34.55 \\
(0.075)\end{array}$ & $6.12(0.410)$ & $\begin{array}{l}23.08 \\
(0.027)\end{array}$ & I $4.32(0.026)$ \\
\hline $\begin{array}{l}\text { 2. I think Saudi female paramedics have similar skill } \\
\text { levels as male paramedics }\end{array}$ & $\begin{array}{l}46.25 \\
(<0.001)\end{array}$ & $\begin{array}{l}66.23 \\
(<0.001)\end{array}$ & $\begin{array}{l}19.24 \\
(0.739)\end{array}$ & $6.38(0.382)$ & $\begin{array}{l}38.56 \\
(<0.00 I)\end{array}$ & $13.46(0.036)$ \\
\hline $\begin{array}{l}\text { 3. I think Saudi Ambulance Services should recruit } \\
\text { female paramedics }\end{array}$ & $\begin{array}{l}59.99 \\
(<0.001)\end{array}$ & $\begin{array}{l}31.6 \\
(<0.001)\end{array}$ & $\begin{array}{l}40.43 \\
(0.019)\end{array}$ & $\begin{array}{l}|5.5| \\
(0.017)\end{array}$ & $\begin{array}{l}28.76 \\
(0.004)\end{array}$ & $12.16(0.059)$ \\
\hline $\begin{array}{l}\text { 4. The reason I never called an Ambulance is because } \\
\text { there are no female paramedics }\end{array}$ & $\begin{array}{l}57.69 \\
(<0.001)\end{array}$ & $\begin{array}{l}54.9 \\
(<0.001)\end{array}$ & $\begin{array}{l}52.16 \\
(0.001)\end{array}$ & $\begin{array}{l}12.17 \\
(0.058)\end{array}$ & $\begin{array}{l}27.32 \\
(0.007)\end{array}$ & $10.42(0.108)$ \\
\hline $\begin{array}{l}\text { 5. I think Saudi female paramedics should treat both } \\
\text { male and female patients in emergencies }\end{array}$ & $\begin{array}{l}71.2 \\
(<0.001)\end{array}$ & $\begin{array}{c}16.12 \\
(0.013)\end{array}$ & $\begin{array}{l}37.68 \\
(0.037)\end{array}$ & $8.46(0.207)$ & $\begin{array}{l}39.81 \\
(<0.001)\end{array}$ & $10.52(0.105)$ \\
\hline $\begin{array}{l}\text { 6. I think female paramedics can deal with children/ } \\
\text { women/elderly people better than male paramedics }\end{array}$ & $\begin{array}{l}70.83 \\
(<0.001)\end{array}$ & $\begin{array}{l}23.83 \\
(<0.001)\end{array}$ & $\begin{array}{l}34.87 \\
(0.07)\end{array}$ & $\begin{array}{l}19.98 \\
(0.003)\end{array}$ & $\begin{array}{l}36.64 \\
(<0.001)\end{array}$ & $9.8(0.133)$ \\
\hline $\begin{array}{l}\text { 7. I prefer a Saudi female paramedic to treat my wife/ } \\
\text { mother/sister }\end{array}$ & $\begin{array}{l}61.47 \\
(<0.001)\end{array}$ & $\begin{array}{l}153.53 \\
(<0.001)\end{array}$ & $\begin{array}{l}28.09 \\
(0.256)\end{array}$ & $5.08(0.534)$ & $\begin{array}{l}34.18 \\
(0.001)\end{array}$ & $8.95(0.176)$ \\
\hline $\begin{array}{l}\text { 8. I think that Saudi female paramedics can balance their } \\
\text { family responsibilities and work duties }\end{array}$ & $\begin{array}{l}65.19 \\
(<0.001)\end{array}$ & $\begin{array}{l}62.16 \\
(<0.001)\end{array}$ & $\begin{array}{l}36.97 \\
(0.044)\end{array}$ & $\begin{array}{l}15.16 \\
(0.019)\end{array}$ & $\begin{array}{l}36.4 \\
(<0.001)\end{array}$ & $6.4(0.38)$ \\
\hline $\begin{array}{l}\text { 9. I think that long hours and shift work might have an } \\
\text { impact on Saudi female paramedics physically, } \\
\text { psychologically and family. }\end{array}$ & $\begin{array}{l}83.09 \\
(<0.001)\end{array}$ & $\begin{array}{l}37.03 \\
(<0.001)\end{array}$ & $\begin{array}{l}18.96 \\
(0.754)\end{array}$ & II.5 (0.074) & $\begin{array}{l}32.95 \\
(0.00 I)\end{array}$ & $4.53(0.606)$ \\
\hline $\begin{array}{l}\text { 10. I think that Saudi female paramedics can deal } \\
\text { emotionally with any cases they attend to as } \\
\text { paramedics }\end{array}$ & $\begin{array}{l}87.64 \\
(<0.001)\end{array}$ & $\begin{array}{l}16.86 \\
(0.01)\end{array}$ & $\begin{array}{l}31.56 \\
(0.138)\end{array}$ & $5.54(0.476)$ & $\begin{array}{l}34.13 \\
(0.00 I)\end{array}$ & $7.72(0.259)$ \\
\hline $\begin{array}{l}\text { II. I think Saudi female paramedics are physically } \\
\text { capable of dealing with any cases they attend as } \\
\text { paramedics }\end{array}$ & $\begin{array}{l}51.76 \\
(<0.001)\end{array}$ & $\begin{array}{l}85.02 \\
(<0.001)\end{array}$ & $\begin{array}{l}16.43 \\
(0.87)\end{array}$ & $\begin{array}{l}11.42 \\
(0.076)\end{array}$ & $\begin{array}{l}45.99 \\
(<0.001)\end{array}$ & $9.64(0.14 I)$ \\
\hline $\begin{array}{l}\text { 12. I think that Saudi female paramedics will be exposed } \\
\text { to violence while working with the Ambulance }\end{array}$ & $\begin{array}{l}64.60 \\
(<0.001)\end{array}$ & $\begin{array}{l}58.24 \\
(<0.001)\end{array}$ & $\begin{array}{l}46.69 \\
(0.004)\end{array}$ & $2.15(0.906)$ & $\begin{array}{l}30.69 \\
(0.002)\end{array}$ & $4.19(0.65 \mathrm{I})$ \\
\hline $\begin{array}{l}\text { 13. I think Saudi female paramedics will suffer from } \\
\text { burnout being a paramedic }\end{array}$ & $\begin{array}{l}47.75 \\
(<0.001)\end{array}$ & $\begin{array}{l}18.0 \\
(0.006)\end{array}$ & $\begin{array}{l}26.43 \\
(0.332)\end{array}$ & $9.47(0.149)$ & $\begin{array}{l}23.63 \\
(0.023)\end{array}$ & $9.03(0.172)$ \\
\hline
\end{tabular}

Notes: Adjusted association - multivariate ordinal logistic regression. The adjusted associations between respondents' demographics and response scale are presented in Table 4. There were significant associations between sex in almost all items, except items 5 and 6 ( $p$-value $<0.05$ ). There were also significant associations, in several items, between age group (items I, 3, 4, 5, 7, 8 and 9), location (items 2, 3, 4, 8, 9, 12 and I3) and job description (items 3, 5, 6 and 7) and the response scale, with p-value < 0.05 .

influencing public perceptions towards female paramedics. Moreover, it highlights the progressive outlook of Saudi Arabian youth in challenging traditional norms and standards associated with the involvement of females in the workforce. As noted by Aldosari, ${ }^{19}$ sex norms have barred females from entering the EMS field due to the mindset exhibited by conservative families. However, the findings of this study indicate that this mindset is changing and evolving given the progressive thinking of younger individuals. For example, Bursztyn et $\mathrm{al}^{20}$ found that younger individuals in Saudi Arabia were supporting women to work outside of their homes and increase their engagement in the Saudi Arabian workforce such as in the EMS discipline. The changes in public perception, based on the age groups of respondents, also reflect the emphasis placed on Saudi Vision 2030 which calls for the inclusion of more female paramedics in the field. ${ }^{12}$ 
Table 4 Multivariate Ordinal Regression for Each Question of Each Variable

\begin{tabular}{|c|c|c|c|c|c|c|}
\hline Questionnaire Items & $\begin{array}{l}\text { Age Group } \\
\text { Coeff }(95 \% \mathrm{Cl})\end{array}$ & $\begin{array}{l}\text { Sex Coeff } \\
(95 \% \mathrm{Cl})\end{array}$ & $\begin{array}{l}\text { Location Coeff } \\
(95 \% \mathrm{Cl})\end{array}$ & $\begin{array}{l}\text { Nationality } \\
\text { Coeff } \\
(95 \% \mathrm{Cl})\end{array}$ & $\begin{array}{l}\text { Job Coeff } \\
(95 \% \mathrm{Cl})\end{array}$ & $\begin{array}{l}\text { Yes Ambulance } \\
\text { Coeff }(95 \% \mathrm{Cl})\end{array}$ \\
\hline $\begin{array}{l}\text { 1. There is a need for female paramedics in the Saudi Arabian Ambulance } \\
\text { Service }\end{array}$ & $\begin{array}{l}-0.10(-0.18 \text { to } \\
-0.04,0.001 *)\end{array}$ & $\begin{array}{c}0.23(0.10 \text { to } \\
-0.36,0.001 *)\end{array}$ & $\begin{array}{l}-0.04(-0.08 \text { to } \\
0.01,0.147)\end{array}$ & $\begin{array}{l}0.09(-0.26 \text { to } \\
0.45,0.604)\end{array}$ & $\begin{array}{l}-0.07(-0.16 \text { to } \\
0.03,0.175)\end{array}$ & $\begin{array}{l}-0.07(0.08 \text { to } 0.08, \\
0.369)\end{array}$ \\
\hline $\begin{array}{l}\text { 2. I think Saudi female paramedics have similar skill levels as male } \\
\text { paramedics }\end{array}$ & $\begin{array}{l}-0.01(0.08 \text { to } \\
0.05,0.670)\end{array}$ & $\begin{array}{l}0.49(0.6 \mathrm{I} \text { to } 0.6 \mathrm{I} \\
\left.<0.00 \mathrm{I}^{\#}\right)\end{array}$ & 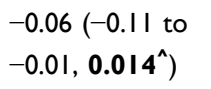 & $\begin{array}{l}0.25(0.59 \text { to } \\
0.59,0.154)\end{array}$ & $\begin{array}{l}-0.05(-0.14 \text { to } \\
0.05,0.309)\end{array}$ & $\begin{array}{l}-0.05(-0.20 \text { to } \\
0.10,0.520)\end{array}$ \\
\hline 3. I think Saudi Ambulance Services should recruit female paramedics & 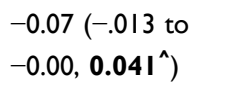 & $\begin{array}{l}0.4 \mathrm{I}(0.28 \text { to } 0.54 \\
\left.<0.00 \mathrm{I}^{\#}\right)\end{array}$ & 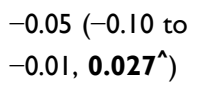 & $\begin{array}{l}0.27(-0.07 \text { to } \\
0.6 I, 0.12 I)\end{array}$ & 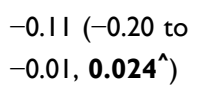 & $\begin{array}{l}-0.06(-0.21 \text { to } \\
0.09,0.431)\end{array}$ \\
\hline $\begin{array}{l}\text { 4. The reason I never called an Ambulance is because there are no female } \\
\text { paramedics }\end{array}$ & $\begin{array}{l}0.17(0.11 \text { to } 0.23 \\
\left.<0.00 I^{\#}\right)\end{array}$ & $\begin{array}{l}0.22(0.08 \text { to } 0.35 \\
\left.0.00 \text { I }^{*}\right)\end{array}$ & $\begin{array}{l}0.05(0.01 \text { to } \\
\left.0.09, \mathbf{0 . 0 2 8}{ }^{\wedge}\right)\end{array}$ & $\begin{array}{l}0.36(0.01 \text { to } \\
\left.0.72,0.044^{\wedge}\right)\end{array}$ & $\begin{array}{l}0.08(-0.02 \text { to } \\
0.12,0.110)\end{array}$ & $\begin{array}{l}-0.06(-0.20 \text { to } \\
0.09,0.435)\end{array}$ \\
\hline $\begin{array}{l}\text { 5. I think Saudi female paramedics should treat both male and female } \\
\text { patients in emergencies }\end{array}$ & $\begin{array}{l}-0.18(-0.25 \text { to } \\
\left.-0.12,<0.00 I^{\#}\right)\end{array}$ & $\begin{array}{l}0.08(-0.06 \text { to } \\
0.21,0.257)\end{array}$ & $\begin{array}{l}-0.04(-0.09 \text { to } \\
0.01,0.095)\end{array}$ & $\begin{array}{l}-0.02(-0.36 \text { to } \\
0.32,0.908)\end{array}$ & $\begin{array}{l}-0.18(-0.28 \text { to } \\
\left.-0.09,<0.00 I^{\#}\right)\end{array}$ & $\begin{array}{l}0.03(-0.12 \text { to } 0.17 \\
0.727)\end{array}$ \\
\hline $\begin{array}{l}\text { 6. I think female paramedics can deal with children/women/elderly people } \\
\text { better than male paramedics }\end{array}$ & $\begin{array}{l}0.02(-0.04 \text { to } \\
0.08,0.537)\end{array}$ & $\begin{array}{l}-0.03(-0.16 \text { to } \\
0.10,0.664)\end{array}$ & $\begin{array}{l}-0.01(-0.05 \text { to } \\
0.04,0.814)\end{array}$ & $\begin{array}{l}0.42(0.08 \text { to } \\
\left.0.77,0.015^{\wedge}\right)\end{array}$ & $\begin{array}{l}0.15(0.06 \text { to } 0.25 \\
0.001 *)\end{array}$ & $\begin{array}{l}-0.20(-0.34 \text { to } \\
-0.05,0.008 *)\end{array}$ \\
\hline 7. I prefer a Saudi female paramedic to treat my wife/mother/sister & $\begin{array}{l}0.16(0.09 \text { to } 0.22 \\
\left.<0.00 I^{\#}\right)\end{array}$ & $\begin{array}{l}-0.84(-0.98 \text { to } \\
\left.-0.7 I,<0.00 I^{\#}\right)\end{array}$ & $\begin{array}{l}0.04(-0.01 \text { to } \\
0.09,0.109)\end{array}$ & $\begin{array}{l}0.03(-0.33 \text { to } \\
0.38,0.883)\end{array}$ & $\begin{array}{l}0.19(0.10 \text { to } 0.29 \\
\left.<0.00 I^{\#}\right)\end{array}$ & $\begin{array}{l}0.13(-0.02 \text { to } 0.28 \\
0.086)\end{array}$ \\
\hline $\begin{array}{l}\text { 8. I think that Saudi female paramedics can balance their family } \\
\text { responsibilities and work duties }\end{array}$ & $\begin{array}{l}-0.09(-0.15 \text { to } \\
-0.03, \mathbf{0 . 0 0 6 *})\end{array}$ & $\begin{array}{l}0.45(0.32 \text { to } 0.58 \\
\left.<0.00 I^{\#}\right)\end{array}$ & $\begin{array}{l}-0.06(-0.10 \text { to } \\
\left.-0.01,0.020^{\wedge}\right)\end{array}$ & $\begin{array}{l}0.19(-0.15 \text { to } \\
0.52,0.277)\end{array}$ & $\begin{array}{l}0.06(-0.03 \text { to } \\
0.16,0.199)\end{array}$ & $\begin{array}{l}0.04(-0.10 \text { to } 0.19, \\
0.584)\end{array}$ \\
\hline $\begin{array}{l}\text { 9. I think that long hours and shift work might have an impact on Saudi } \\
\text { female paramedics physically, psychologically and family. }\end{array}$ & $\begin{array}{l}0.21(0.15 \text { to } 0.28 \\
\left.<0.00 I^{\#}\right)\end{array}$ & $\begin{array}{l}-0.38(-0.51 \text { to } \\
\left.-0.24,<0.00 I^{\#}\right)\end{array}$ & 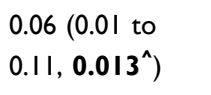 & $\begin{array}{l}-0.19(-0.54 \text { to } \\
0.16,0.287)\end{array}$ & $\begin{array}{l}-0.08(-0.17 \text { to } \\
0.02,0.101)\end{array}$ & $\begin{array}{l}-0.01(-0.15 \text { to } \\
0.14,0.937)\end{array}$ \\
\hline $\begin{array}{l}\text { 10. I think that Saudi female paramedics can deal emotionally with any cases } \\
\text { they attend to as paramedics }\end{array}$ & $\begin{array}{l}0.06(-0.00 \text { to } \\
0.12,0.069)\end{array}$ & 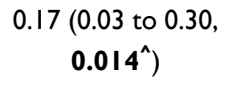 & $\begin{array}{l}-0.01(-0.06 \text { to } \\
0.03,0.617)\end{array}$ & $\begin{array}{l}-0.12(-0.47 \text { to } \\
0.22,0.488)\end{array}$ & $\begin{array}{l}0.09(-0.01 \text { to } \\
0.18,0.068)\end{array}$ & $\begin{array}{l}-0.07(-0.22 \text { to } \\
0.08,0.347)\end{array}$ \\
\hline $\begin{array}{l}\text { II. I think Saudi female paramedics are physically capable of dealing with } \\
\text { any cases they attend as paramedics }\end{array}$ & $\begin{array}{l}-0.03(-0.09 \text { to } \\
0.03,0.361)\end{array}$ & $\begin{array}{l}0.52(0.39 \text { to } 0.65 \\
\left.<0.00 \mathrm{I}^{\#}\right)\end{array}$ & $\begin{array}{l}-0.02(-0.07 \text { to } \\
0.02,0.358)\end{array}$ & $\begin{array}{l}0.41(0.07 \text { to } \\
\left.0.75,0.017^{\wedge}\right)\end{array}$ & $\begin{array}{l}0.09(-0.00 \text { to } \\
0.18,0.058)\end{array}$ & $\begin{array}{l}0.03(-0.12 \text { to } 0.17 \\
0.710)\end{array}$ \\
\hline $\begin{array}{l}\text { 12. I think that Saudi female paramedics will be exposed to violence while } \\
\text { working with the Ambulance }\end{array}$ & $\begin{array}{l}0.01(-0.05 \text { to } \\
0.07,0.772)\end{array}$ & $\begin{array}{l}0.25(0.12 \text { to } 0.38 \\
\left.<0.00 I^{\#}\right)\end{array}$ & $\begin{array}{l}0.06(0.01 \text { to } \\
\left.0.11,0.012^{\wedge}\right)\end{array}$ & $\begin{array}{l}-0.20(-0.55 \text { to } \\
0.15,0.261)\end{array}$ & $\begin{array}{l}-0.03(-0.12 \text { to } \\
0.06,0.492)\end{array}$ & $\begin{array}{l}-0.07(-0.22 \text { to } \\
0.07,0.324)\end{array}$ \\
\hline $\begin{array}{l}\text { 13. I think Saudi female paramedics will suffer from burnout being } \\
\text { a paramedic }\end{array}$ & $\begin{array}{l}0.00(-0.06 \text { to } \\
0.06,0.94 I)\end{array}$ & $\begin{array}{l}-0.14(-0.27 \text { to } \\
\left.-0.01,0.032^{\wedge}\right)\end{array}$ & $\begin{array}{l}0.06(0.01 \text { to } \\
\left.0.10,0.015^{\wedge}\right)\end{array}$ & $\begin{array}{l}-0.26(-0.62 \text { to } \\
0.09,0.147)\end{array}$ & $\begin{array}{l}-0.04(-0.14 \text { to } \\
0.05,0.350)\end{array}$ & $\begin{array}{l}0.02(-0.12 \text { to } 0.17, \\
0.767)\end{array}$ \\
\hline
\end{tabular}

Notes: ${ }_{p} p<0.001,{ }^{*} p<0.01,{ }_{p}<0.05$. 
In line with these perceptions, it can be noted that advancement within Saudi society and the emergence of a progressive mindset is associated with the development of positive attitudes towards female workforce participation, which is especially reflected by younger people, in comparison with older people who still hold traditional views and values. The inclusion of female paramedics in EMS was welcomed by respondents who believed in the empowerment of women and their ability to make career decisions regardless of cultural, social, and traditional barriers, which previously barred them from advancing in their chosen occupation. Moreover, Nosheen et $\mathrm{al}^{21}$ stated that typical old age community norms need to be changed and evolve in line with the changes in the Saudi community, where the younger age groups are likely to be more open to such changes.

\section{Living Area}

The findings of the research noted that residential areas affected community perceptions regarding female paramedics in the field of ambulance services. Statistically significant differences also did not exist regarding other questions, such as the preference of female paramedics for treating female patients. These results suggest that social characteristics and differences between various residential areas of Riyadh did not determine the community's perceptions of female paramedics and respondents generally shared unanimous views. In a study conducted by Alanazy et al, ${ }^{22}$ challenges and barriers faced by EMTs in delivering their service in urban and rural areas were examined; however, the study did not classify the residential area as a variable for assessing respondents' preferences for female versus male paramedics. Nonetheless, the research noted disparities between delivery of EMS in residential areas and highlighted that people living in rural areas of the Riyadh region believed that EMS was less reliable compared to urban centers. ${ }^{22}$

Further statistical examination presented a significant statistical difference in items $(2,3,4,8,9$ and 12) related to a residential area, where most respondents preferred female paramedics in the treatment of their female family members. A study conducted by $\mathrm{Wang}^{23}$ on the Syrian refugee population in Jordan found that residential area of individuals impacted their perceptions of EMS. Where Syrian refugees lived in urban areas, host communities within Jordan perceived that EMS available in the area were satisfactory because of quicker accessibility and lesser wait times. This observation suggests that people in various residential areas have different experiences with EMS and these experiences help formulate their views and preferences. Accordingly, other socio-cultural subfactors that exist within a residential area, such as level of education, can also shape perceptions. For example, individuals with more open mindsets may be more accepting of female paramedics, in comparison with those with lower levels of education who do not feel comfortable with the idea of being treated by female paramedics. Nonetheless, analysis of community perceptions regarding female paramedics in the light of residential areas is a novel aspect of this research and has not been performed in comparable studies focusing on female paramedics in Saudi Arabia.

\section{Job Description}

Regarding the perception of medical and non-medical professional respondents, our research found that there was a significant statistical difference between job description and related items (3, 5, 6 and 7), where the most respondents supported recruiting female paramedics in the field of EMS due to the culture and traditional conservativity. Both groups expressed their perceptions throughout their experiences and preferences, for example of that the medical profession respondents may face difficulties to attend some of female cases due to their conservativity where non-medical respondents preferred female paramedics to be available in women-only areas such as female universities and women's health centers. A research conducted by Alharthy et al, ${ }^{10}$ which examined the public perceptions of female paramedics, categorized the sample based on medical and non-medical respondents, the majority of both medical and non-medical are supporting of recruiting female paramedics to be included in the EMS discipline due to the Saudi culture and tradition.

\section{Limitations}

This is the first large study that contributes to exploring the Saudi public's perceptions of female paramedics. The study was conducted only in Riyadh, the capital city of Saudi Arabia, and therefore, generalizability is affected by this. Convenience sampling and self-report are considered another limitation in this study, which may affect the 
generalizability and reliability of the result. However, this technique was considered sufficient and affordable for data collection with the public and the sample size was adequate for drawing conclusions. Furthermore, questionnaire translation is considered another limitation in this study through the potential lack of context, cultural nuances, homonyms and differences in concepts. ${ }^{24}$ Therefore, future research should assess the public's perceptions from other Saudi regions and also other Gulf countries about the availability of female paramedics in the field of paramedicine.

\section{Conclusion}

This study explored perceptions of the Saudi public towards Saudi female paramedics in the Riyadh region in Saudi Arabia. The results of the study indicate the opinions of Saudi society to include Saudi female paramedics in the EMS workforce by sex, age groups and residential area. These results may assist Saudi healthcare organizations to acknowledge the Saudi public's perceptions and empower Saudi female paramedics in their organizations to be part of the front line in EMS settings. Future research is needed to include other cities to generalize national public perceptions around the country.

\section{Abbreviations}

EMS, Emergency Medical Services; EMTs, Emergency Medical Technicians; STROBE, Strengthening of the Reporting of Observational Studies in Epidemiology; SPSS, Statistical Package for Social Sciences; Cis, confidence intervals; Coef, Coefficient.

\section{Data Sharing Statement}

All data generated and analyzed during this study are included in this published article.

\section{Ethical Statement}

Consent was implied when the respondent submitted the survey via the QR code or Qualtrics links. The study was approved by the Monash University Human Ethics Committee (project ID\# 27093) and King Saud University ethical committee (Project ID\# E-21-5652). The main ethical issues considered were respect for person, beneficence and that no harm was caused to the respondent, informed consent, and privacy of the respondents.

\section{Author Contributions}

All authors contributed to data analysis, drafting, or revising the article, have agreed on the journal to which the article will be submitted, gave final approval of the version to be published, and agree to be accountable for all aspects of the work.

\section{Funding}

This manuscript was not funded by any institutions or vendors.

\section{Disclosure}

The authors declare that they have no known competing financial interests or personal relationships that could have appeared to influence the work reported in this paper.

\section{References}

1. AlShammari T, Jennings P, Williams B. National study of emergency medical services core competencies: a confirmatory factor analysis. Australas J Paramed. 2019;16. doi:10.33151/ajp.16.706

2. Sheikhbardsiri H, Khademipour G, Nekoei-Moghadam M, Aminizadeh M. Motivation of the nurses in pre-hospital emergency and educational hospitals emergency in the southeast of Iran. Int J Health Plann Manage. 2018;33(1):255-264. doi:10.1002/hpm.2455

3. Khattab E, Sabbagh A, Aljerian N, et al. Emergency medicine in Saudi Arabia: a century of progress and a bright vision for the future. Int J Emerg Med. 2019;12(1):1-8. doi:10.1186/s12245-019-0232-0

4. Saudi Red Crescent Authority. History of SRCA 2013; 2020. Available from: http://www.srca.org.sa/history.aspx. Accessed January $10,2021$. 
5. AlShammari T, Jennings P, Williams B. Evolution of emergency medical services in Saudi Arabia. J Emerg Med Trauma Acute Care. 2017;2017 (1):4. doi:10.5339/jemtac.2017.4

6. Mahfouz A, Abdel Moneim I, Khan M, et al. Primary health care emergency services in Abha district of southwestern Saudi Arabia. East Mediterr Health J. 2007;13(1):103-112.

7. Naseem S, Dhruva K. Issues and challenges of Saudi female labor force and the role of vision 2030. Int J Econ Financial Issues. $2017 ; 7(4): 23-27$.

8. Sabir A, Zenaidi K. Saudi Arabia reforms: the changing face of Saudi women at workplace with a vision of 2030. Am J Manag Sci Eng. 2019;4 (1):1-7. doi:10.11648/j.ajmse.20190401.11

9. Alobaid AM, Gosling C, Mckenna L, Williams B. Gendered organizational theory and glass ceiling: application to female Saudi paramedics in the workplace. Saudi J Health Sci. 2021;9:177-182. doi:10.4103/sjhs.sjhs_56_20

10. Alharthy N, Alswaes S, Almaziad A, Alenazi N, Abdallah M, Alshehry M. Public perception of female paramedics at king Abdulaziz medical city, Saudi Arabia. Int J Emerg Med. 2018;11(1):1-5. doi:10.1186/s12245-018-0217-4

11. Hamam A, Bagis M, AlJohani K, Tashkandi A. Public awareness of the EMS system in Western Saudi Arabia: identifying the weakest link. Int J Emerg Med. 2015;8(1):1-7. doi:10.1186/s12245-015-0070-7

12. ALobaid AM, Gosling C, McKenna L, Williams B. Perceptions of EMS leaders and supervisors on the challenges faced by female paramedics in Riyadh Saudi Arabia: a qualitative study. Int J Emerg Services. 2021;10(2):235-246. doi:10.1108/IJES-09-2020-0055

13. Von Elm E, Altman DG, Egger M, Pocock SJ, Gøtzsche PC, Vandenbroucke JP. The Strengthening the Reporting of Observational Studies in Epidemiology (STROBE) statement: guidelines for reporting observational studies. Ann Intern Med. 2007;147(8):573-577. doi:10.1016/j. ijsu.2014.07.013

14. General Authority for Statistics. Population by age groups and gender mid year; 2020. Available from: https://www.stats.gov.sa/sites/default/files/ Population\%20by\%20Age\%20Groups\%20\%2Cand\%20Gender_0.pdf. Accessed August 17, 2021.

15. ALobaid AM, Gosling CM, Khasawneh E, McKenna L, Williams B. Challenges faced by female healthcare professionals in the workforce: a scoping review. J Multidiscip Healthc. 2020;13:681-691. doi:10.2147/JMDH.S254922

16. Toma G, Guetterman TC, Yaqub T, Talaat N, Fetters MD. A systematic approach for accurate translation of instruments: experience with translating the Connor-Davidson Resilience Scale into Arabic. Methodol Innov. 2017;10(3):1-10. doi:10.1177/2059799117741406

17. Barrow JM, Brannan GD, Khandhar PB. Research ethics. StatPearls [Internet] Web site; 2020. Available from: https://www.ncbi.nlm.nih.gov/ books/NBK459281/. Accessed August 17, 2021.

18. General Authority for Statistics. Saudi population by age groups and gender; 2021. Available from: https://www.stats.gov.sa/sites/default/files/ Population\%20by\%20Age\%20Groups\%20\%2Cand\%20Gender_0.pdf. Accessed January 26, 2022.

19. Aldosari H. The Effect of Gender Norms on Women's Health in Saudi Arabia. Washington, DC: Arab Gulf States Institute in Washington; 2017.

20. Bursztyn L, González AL, Yanagizawa-Drott D. Misperceived social norms: women working outside the home in Saudi Arabia. Am Econ Rev. 2020;110(10):2997-3029. doi:10.1257/aer.20180975

21. Nosheen F, Naveed HAT, Qasim TB. Is education the only way to attain women's empowerment goal? An empirical view. PalArchs $J$ Archaeol Egypt/Egyptol. 2021;18(5):438-445.

22. Alanazy ARM, Fraser J, Wark S. Organisational factors affecting emergency medical services' performance in rural and urban areas of Saudi Arabia. BMC Health Serv Res. 2021;21(1):1-8. doi:10.1186/s12913-021-06565-3

23. Wang ES. Perceptions as a Barrier to Emergency Medical Services Utilization Among Syrian Refugees in Jordan. Public Health, The George Washington University; 2018.

24. Omona J, Groce N. Translation and research outcomes of the Bridging the Gap project: a case of the Luo language, spoken in northern Uganda. Transl Stud. 2021;1-16. doi:10.1080/14781700.2021.1888784

Advances in Medical Education and Practice

Dovepress

\section{Publish your work in this journal}

Advances in Medical Education and Practice is an international, peer-reviewed, open access journal that aims to present and publish research on Medical Education covering medical, dental, nursing and allied health care professional education. The journal covers undergraduate education, postgraduate training and continuing medical education including emerging trends and innovative models linking education, research, and health care services. The manuscript management system is completely online and includes a very quick and fair peer-review system. Visit http://www.dovepress.com/testimonials.php to read real quotes from published authors.

Submit your manuscript here: http://www.dovepress.com/advances-in-medical-education-and-practice-journal 